\title{
Neurovascular hand symptoms in relation to cold exposure in northern Sweden: a population-based study
}

\author{
Albin Stjernbrandt ${ }^{1,3}$ (1) Bodil Björr $^{1,3} \cdot$ Martin Andersson $^{1,3} \cdot$ Lage Burström $^{1}$ • \\ Ingrid Liljelind $^{1,3} \cdot$ Tohr Nilsson ${ }^{1} \cdot$ Ronnie Lundström $^{1,2} \cdot$ Jens Wahlström $^{1,3}$
}

Received: 14 June 2016 / Accepted: 6 April 2017 / Published online: 11 April 2017

(C) The Author(s) 2017. This article is an open access publication

\begin{abstract}
Purpose To describe the self-reported ambient cold exposure in northern Sweden and to relate the level of cumulative cold exposure to the occurrence of sensory and vascular hand symptoms. We hypothesize that cold exposure is positively related to reporting such symptoms.

Methods A questionnaire about cold exposure and related symptoms was sent out to 35,144 subjects aged 18-70 years and living in northern Sweden.

Results A total of 12,627 out of 35,144 subjects returned the questionnaire (response rate $35.9 \%$ ). Subjects living in the rural alpine areas reported more extensive cold exposure both during work and leisure time compared to the urbanized coastal regions. Frostbite in the hands was present in $11.4 \%$ of men and $7.1 \%$ of women, cold sensitivity was present in 9.7 and $14.4 \%$, and Raynaud's phenomenon was present in $11.0 \%$ of men and $14.0 \%$ of women. There was a positive association between cumulative cold exposure and neurovascular hand symptoms.

Conclusion The present study demonstrates that the cold environment in northern Sweden might be an underestimated health risk. Our hypothesis that cold exposure
\end{abstract}

Electronic supplementary material The online version of this article (doi:10.1007/s00420-017-1221-3) contains supplementary material, which is available to authorized users.

Albin Stjernbrandt

albin.stjernbrandt@umu.se

1 Department of Public Health and Clinical Medicine, Umeå University, 90187 Umeå, Sweden

2 Department of Radiation Sciences, Umeå University, 901 87 Umeå, Sweden

3 Occupational and Environmental Medicine, University Hospital of Umeå, 90185 Umeå, Sweden is positively related to reporting of neurovascular hand symptoms was supported by our findings. In addition, such symptoms were common not only in conjunction with an overt cold injury. Our results warrant further study on pathophysiological mechanisms and suggest the need for confirmatory prevalence studies to support national public health planning.

Keywords Cold exposure · Sweden · Hand · Frostbite · Cold sensitivity $\cdot$ Raynaud's phenomenon

\section{Introduction}

Living in a cold climate is associated with numerous adverse health effects (Hassi et al. 2005; Makinen and Hassi 2009). A number of studies have documented increased wintertime morbidity and mortality, especially in the respiratory and cardiovascular systems (Gasparrini et al. 2015; Raatikka et al. 2007; The Eurowinter Group 1997). Cold exposure can also cause specific injuries to the extremities, such as frostbite and chilblains, and is associated with long-term neurological and vascular dysfunction (Carlsson et al. 2016; Imray and Castellani 2012). Different pathophysiological mechanisms of such cold injuries have been studied and it has been shown that reduced tissue temperature due to ambient cold exposure can lead to several detrimental vascular effects, such as vasoconstriction, ischemia-induced endothelial damage, hemoconcentration, and the creation of free radicals (Thomas and Oakley 2002). Some of these effects are believed to contribute to vascular hand symptoms, such as Raynaud's phenomenon (Garner et al. 2015). When it comes to the peripheral nerves, apart from direct damage from cooling, the ischemic 
vascular effects mentioned above can also cause nerve dysfunction through effects on the vasa nervorum, the small arteries that supply blood flow to the peripheral nerves (Thomas and Oakley 2002).

Cold sensitivity has previously been defined as an exaggerated or abnormal reaction to cold exposure causing discomfort or the avoidance of cold (Kay 1985), and it has often been studied in conjunction with hand injuries, such as digital amputations or hand-arm vibration injury (Carlsson et al. 2010; Lithell et al. 1997). The pathophysiological mechanisms in cold sensitivity might involve both neurological and vascular aspects (Hope et al. 2014; Thomas and Oakley 2002). To the authors' knowledge, cold sensitivity has not previously been investigated in large-scale population-based studies. However, one Swedish study included a small sample of subjects from the general population $(N=94)$, (Carlsson et al. 2010).

Regarding exposure to cold, temperatures at or below $10{ }^{\circ} \mathrm{C}$ are defined as ambient cold exposure in occupational health standards (International Organization for Standardization 2008). The experience of being cold can also be defined from a subjective standpoint regardless of the ambient temperature (Makinen and Hassi 2002). Cold exposure can occur during both work and leisure time and is often associated with aggravating environmental conditions, such as wind, rain, or snow (Keim et al. 2002). Indoor work with cold storage, contact with cold objects, and immersion in cold water can also contribute (Baldus et al. 2012). In addition, the effects of ambient cold exposure are modified by individual factors, such as sex, age, nutritional status, pre-existing diseases, medication, thermal insulation of clothing, and activity level (Raatikka et al. 2007). Swedish national statistics report that $22 \%$ of working men and $11 \%$ of working women in Sweden are occupationally exposed to cold for more than one quarter of their working hours (Swedish Work Environment Authority 2014). Living in the northern parts of Sweden can also result in significant leisure-time cold exposure, but national statistics for such exposure are not available. Large-scale, questionnaire-based studies of cold-related health effects have been undertaken in Finland (Makinen et al. 2009; Nayha et al. 2011; Raatikka et al. 2007), but such studies are lacking in Sweden.

The aim of the present study was to describe the selfreported ambient cold exposure in northern Sweden and to relate the level of cumulative cold exposure to the reported occurrence of sensory and vascular hand symptoms. We hypothesize that cold exposure is positively related to reporting such symptoms.

\section{Methods}

\section{Participants and data collection}

The Cold and Health in Northern Sweden (CHINS) studies were launched in early 2015 and consist of several questionnaire-based surveys, of which this paper represents the first publication. The present study had a descriptive cross-sectional design and focused on the characteristics of the baseline cohort and the occurrence of hand symptoms. It was conducted in the four northernmost counties in Sweden: Norrbotten, Västerbotten, Västernorrland, and Jämtland. The study region holds a population of approximately 880,000 people and is located between $62^{\circ} \mathrm{N}$ and $69^{\circ} \mathrm{N}$ latitude with a mixed subarctic and temperate climate. The data collection was initiated on the fifth of February 2015 and was ended on the fifth of May 2015. The mean monthly temperature during the study period ranged from -9.4 to $4.9^{\circ} \mathrm{C}$, with the lowest temperatures recorded in the alpine regions and the highest in the coastal regions (Swedish Metrological and Hydrological Institute 2015).

The data collection was performed by means of a mail-in survey on a sample of men and women between 18 and 70 years of age living in the study area who were drawn from the national Swedish population register. The study region was subdivided into 13 climate zones (Fig. 1) depending on the mean annual temperature (The Swedish Horticultural Society 2015), and a fixed number of questionnaires was allocated to each of these climate zones ( $N=1,350$ per zone, $N=17,550$ in total), after which the remaining number $(N=17,594)$ was proportionally distributed according to the population size in each climate zone. This semi-randomized approach was chosen to ensure a sufficient sample from sparsely populated areas, where cold exposure can be profound. One questionnaire per individual was sent by mail, without subsequent reminders.

\section{Study design}

The study questionnaire included 38 items and was designed by a ten-person team consisting of three occupational and environmental physicians, two ergonomists, two occupational and environmental hygienists and three engineers. The questionnaire collected baseline data on demographic and anthropometric variables in the form of place of residence, sex, age, height, and weight. The daily use of tobacco, either cigarettes or snuff, was asked about. Other questions asked if the study participants 


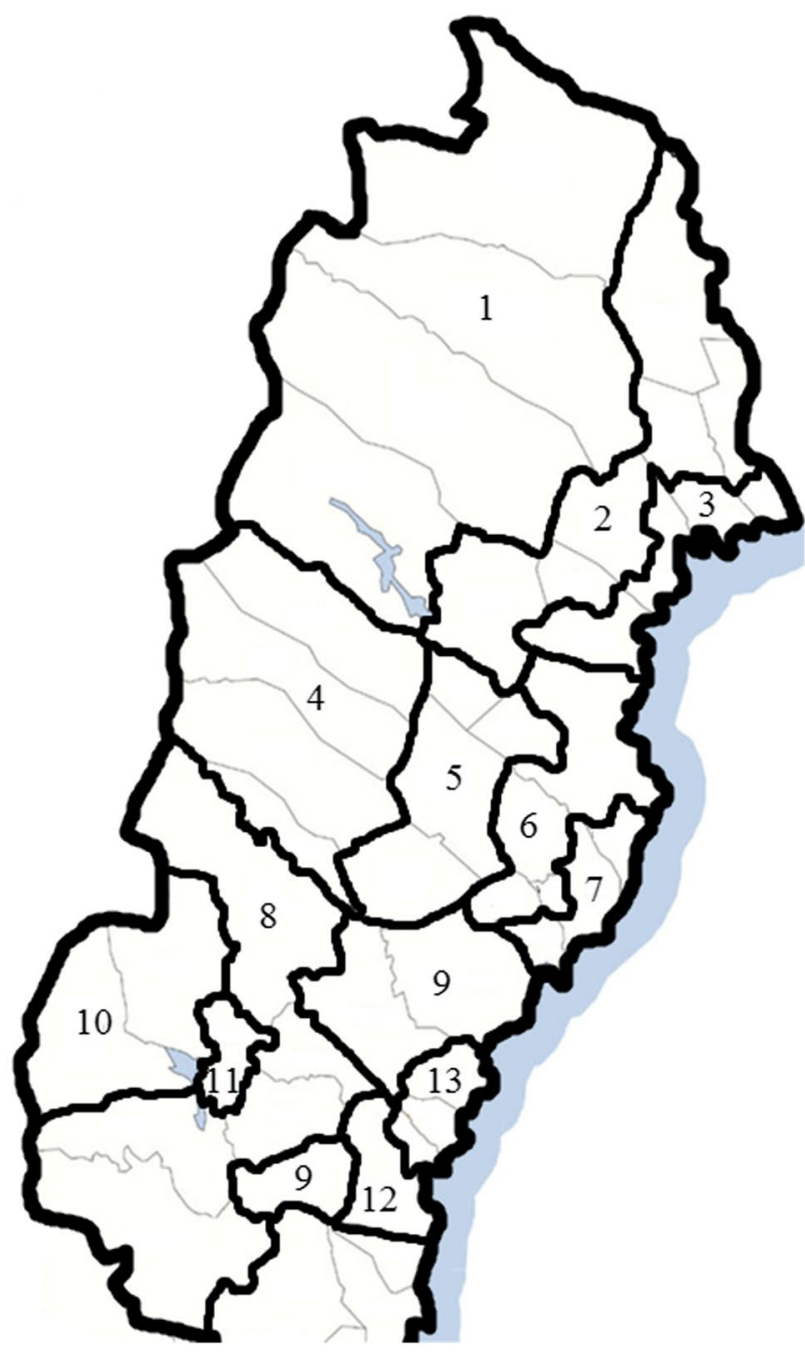

Fig. 1 Climate zones of northern Sweden. The data collection was stratified according to the 13 climate zones that are shown with numbers in the figure. The ninth climate zone is made up of two different areas. Thick black lines show the border of each climate zone, and thin grey lines depict the different counties

had been diagnosed by a physician for any of the following: hypertension, angina pectoris, myocardial infarction, stroke, asthma, chronic obstructive pulmonary disease, diabetes mellitus, joint disorders, or migraine. The occupation of the study participants was collected in free text and then coded in accordance with the International Standard Classification of Occupations (International Labour Organization 2012). Geographical location was determined by postal code and stratified into 44 municipalities that were then grouped together to form three broad categories-coastal, inland, and alpine.

We defined cold exposure as being outside during the winter time study period or in cold environments indoors. The participants were asked to specify their exposure during work and leisure time by grading their exposure on two separate cold exposure variables:

(1) "During work I am exposed to outdoor or cold environments."

(2) "During leisure time I am exposed to outdoor or cold environments."

The answers were graded on a numerical scale in whole numbers ranging from 1 ("do not agree") to 10 ("fully agree"). In the analyses, data were categorized into a four categories, where 1 was categorized as "none", 2-4 as "low", 5-7 as "medium", and 8-10 as "high" exposure. For logistic regression analyses, the occupational and leisuretime exposure variables were summed to form a cumulative exposure variable ranging from 2 ("do not agree") to 20 ("fully agree"). This variable was then divided into quartiles. Through this approach, the contribution of cold exposure was assumed to be of similar importance regardless of whether it occurred during work or leisure time.

Frostbite was categorized according to location (hands, feet, or face) and as first degree (white spots), second degree (blisters), or third degree (blood-filled blisters), inspired by a previously described classification system (Imray et al. 2009). For questions regarding the sensory and vascular function of the hands, a previously tested descriptive scale was used (Hagberg et al. 2008). Questions were posed, such as: "Have you experienced decreased touch perception in your hand?" The answers were given on a four-grade scale as "none", "insignificant", "somewhat", or "a lot". Answering "somewhat" or "a lot" was considered a positive response. Cold sensitivity was determined with the statement, "I am over-sensitive to cold", to which the study participant could answer on a fixed numerical scale ranging from 1 ("do not agree") to 10 ("agree completely"), where an answer of 4 or more was considered a positive response. The occurrence of Raynaud's phenomenon was investigated through a single item question, "Does one or more of your fingers turn white (as shown on picture) when exposed to moisture or cold?", and this was supported by a standardized color chart that has previously been shown to increase the diagnostic specificity (Negro et al. 2008).

\section{Statistical analysis}

The statistical dependence of the two cold exposure variables was measured using Spearman's rank correlation coefficient. For the relationship between the cumulative exposure variable (leisure time and occupational cold exposure) and different symptoms, odds ratios with $95 \%$ confidence intervals were calculated using logistic regression. $P$ 
values $\leq 0.05$ were considered statistically significant. All statistical analyses were performed with IBM SPSS Statistics for Windows (version 23.0, IBM Corporation, Armonk, NY, USA).

\section{Results}

\section{Participants}

A total of 35,144 questionnaires were sent out, of which 34,822 reached their intended addressees and 12,627 were filled in and returned for a final response rate of $35.9 \%$. An analysis of non-responders revealed minor demographical differences in terms of sex, age, and home district as compared to the responders (Online Resource
1). The response rate increased with age and was slightly higher among women.

The final study population consisted of $45.5 \%$ men and $54.5 \%$ women, and the mean age was 52 and 50 years, respectively. Men had a higher body mass index than women $\left[26.7\right.$ (standard deviation 4.0 ) $\mathrm{kg} / \mathrm{m}^{2}$ versus 25.6 (standard deviation 4.9 ) $\mathrm{kg} / \mathrm{m}^{2}$ ]. Daily smoking was reported by $7.2 \%$ of men and $9.8 \%$ of women, and daily use of snuff was reported by 23.2 and $8.5 \%$, respectively. The anthropometric data and occurrence of diseases are presented in detail in Table 1.

Both occupational and leisure-time cold exposures were higher among men than women, and high levels of cold exposure were inversely proportional to age (Table 2). Study participants living in alpine areas more frequently reported high cold exposure during work

Table 1 Study group characteristics

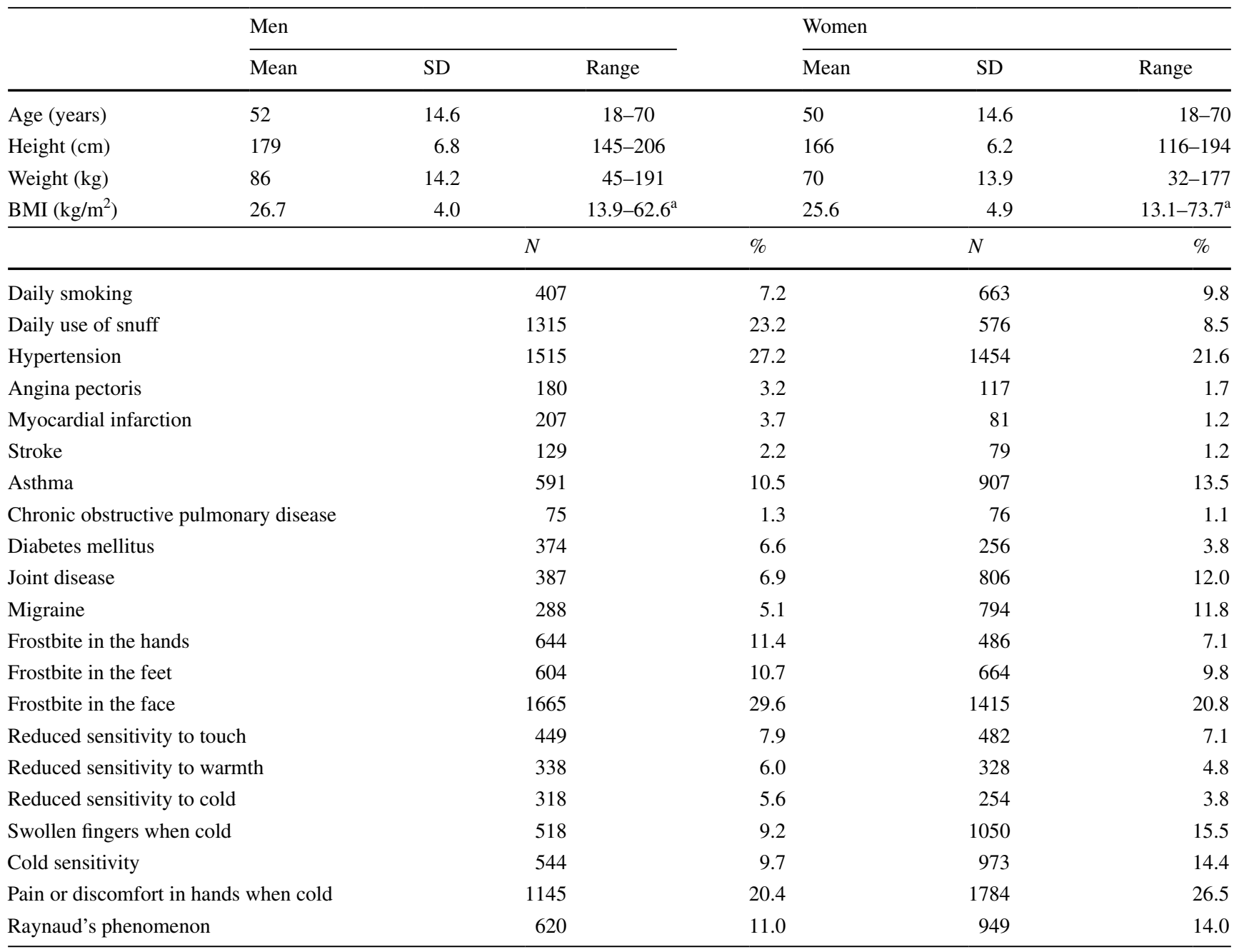

Anthropometric data, tobacco habits, diseases, and symptoms in the study group

$S D$ standard deviation, $B M I$ body mass index

a The range is affected by outliers. When these were excluded (BMI $<15$ or $>40$, men $N=53$; women $N=89$ ), the mean BMI was 26.6 for men and 25.4 for women 
Table 2 Occupational and leisure-time cold exposure

\begin{tabular}{|c|c|c|c|c|c|c|c|c|}
\hline & \multicolumn{4}{|c|}{ Occupational cold exposure } & \multicolumn{4}{|c|}{ Leisure-time cold exposure } \\
\hline & None (NRS 1) & $\begin{array}{l}\text { Low (NRS } \\
2-4)\end{array}$ & $\begin{array}{l}\text { Medium (NRS } \\
5-7 \text { ) }\end{array}$ & $\begin{array}{l}\text { High (NRS } \\
8-10)\end{array}$ & None (NRS 1) & $\begin{array}{l}\text { Low (NRS } \\
2-4)\end{array}$ & $\begin{array}{l}\text { Medium (NRS } \\
5-7)\end{array}$ & $\begin{array}{l}\text { High (NRS } \\
8-10)\end{array}$ \\
\hline & $N(\%)$ & $N(\%)$ & $N(\%)$ & $N(\%)$ & $N(\%)$ & $N(\%)$ & $N(\%)$ & $N(\%)$ \\
\hline \multicolumn{9}{|l|}{ Sex } \\
\hline Male & $2488(45.7)$ & $981(18.0)$ & $989(18.2)$ & $988(18.1)$ & $480(8.6)$ & $1208(21.5)$ & $2256(40.2)$ & $1663(29.7)$ \\
\hline Female & $4525(69.2)$ & $853(13.0)$ & $597(9.1)$ & $563(8.6)$ & $986(14.7)$ & $1598(23.9)$ & $2448(36.5)$ & $1666(24.9)$ \\
\hline \multicolumn{9}{|l|}{ Age (years) } \\
\hline $18-31$ & $908(51.3)$ & $312(17.6)$ & $279(15.8)$ & $270(15.3)$ & $181(10.2)$ & $428(24.1)$ & $688(38.7)$ & $481(27.1)$ \\
\hline $32-44$ & $1181(55.9)$ & $346(16.4)$ & $292(13.8)$ & $293(13.9)$ & $157(7.4)$ & 459 (21.6) & $829(39.1)$ & 677 (31.9) \\
\hline $45-57$ & $1875(54.9)$ & $595(17.4)$ & $473(13.9)$ & $472(13.8)$ & $326(9.5)$ & $735(21.5)$ & $1361(39.8)$ & $996(29.1)$ \\
\hline $58-70$ & $3049(65.0)$ & $581(12.4)$ & $542(11.6)$ & $516(11.0)$ & $802(16.1)$ & $1184(23.7)$ & $1826(36.6)$ & $1175(23.6)$ \\
\hline \multicolumn{9}{|l|}{ Region } \\
\hline Alpine & $1289(49.8)$ & $434(16.8)$ & $416(16.1)$ & $449(17.3)$ & $234(8.8)$ & $445(16.8)$ & 995 (37.5) & $982(37.0)$ \\
\hline Inland & 1787 (57.4) & $463(14.9)$ & 434 (13.9) & $428(13.8)$ & $371(11.6)$ & $683(21.3)$ & $1282(39.9)$ & $876(27.3)$ \\
\hline Coastal & 3937 (62.7) & 937 (14.9) & $736(11.7)$ & $674(10.7)$ & $861(13.4)$ & $1678(26.1)$ & 2427 (37.7) & $1471(22.9)$ \\
\hline \multicolumn{9}{|l|}{ Occupation } \\
\hline $\begin{array}{l}\text { Armed forces } \\
\text { occupa- } \\
\text { tions }\end{array}$ & $1(3.1)$ & $2(6.3)$ & $5(15.6)$ & $24(75.8)$ & $0(0)$ & $6(19.4)$ & $9(29.0)$ & $16(51.6)$ \\
\hline Managers & 305 (68.7) & $83(18.7)$ & 38 (8.6) & $18(4.1)$ & $32(7.2)$ & 83 (18.6) & $186(41.6)$ & $146(32.7)$ \\
\hline Professionals & $1242(61.8)$ & $335(16.7)$ & $203(10.1)$ & $230(11.4)$ & 157 (7.8) & $483(24.0)$ & $774(38.5)$ & $596(29.7)$ \\
\hline $\begin{array}{l}\text { Technicians } \\
\text { and associ- } \\
\text { ate profes- } \\
\text { sionals }\end{array}$ & $687(58.9)$ & $220(18.9)$ & 147 (12.6) & $113(9.7)$ & $79(6.8)$ & $259(22.3)$ & $491(42.2)$ & $334(28.7)$ \\
\hline $\begin{array}{l}\text { Clerical } \\
\text { support } \\
\text { workers }\end{array}$ & 765 (75.5) & $112(11.1)$ & $67(6.6)$ & $69(6.8)$ & $111(10.9)$ & 299 (29.5) & 379 (37.3) & $226(22.3)$ \\
\hline $\begin{array}{l}\text { Service and } \\
\text { sales work- } \\
\text { ers }\end{array}$ & $974(54.1)$ & 305 (16.9) & $275(15.3)$ & $248(13.8)$ & $214(11.9)$ & $399(22.2)$ & $698(38.8)$ & $490(27.2)$ \\
\hline $\begin{array}{l}\text { Skilled agri- } \\
\text { cultural, } \\
\text { forestry, } \\
\text { and fishery } \\
\text { workers }\end{array}$ & $18(8.5)$ & $15(7.1)$ & $37(17.5)$ & $142(67.0)$ & $16(7.5)$ & $20(9.3)$ & $62(29.0)$ & $116(54.2)$ \\
\hline $\begin{array}{l}\text { Crafts and } \\
\text { related } \\
\text { trades } \\
\text { workers }\end{array}$ & $151(23.3)$ & $120(18.5)$ & $184(28.4)$ & $192(29.7)$ & $27(4.2)$ & $125(19.3)$ & $300(46.4)$ & $194(30.0)$ \\
\hline $\begin{array}{l}\text { Plant and } \\
\text { machine } \\
\text { operators } \\
\text { and assem- } \\
\text { blers }\end{array}$ & $180(24.3)$ & $163(22.0)$ & 204 (27.6) & $193(26.1)$ & $51(6.9)$ & $130(17.6)$ & 309 (41.8) & $250(33.8)$ \\
\hline $\begin{array}{l}\text { Elementary } \\
\text { occupa- } \\
\text { tions }\end{array}$ & $125(43.3)$ & $56(19.4)$ & 43 (14.9) & $65(22.5)$ & $43(14.9)$ & $87(30.1)$ & $90(31.1)$ & 69 (23.9) \\
\hline $\begin{array}{l}\text { Self- } \\
\text { employed }\end{array}$ & $86(37.6)$ & $42(18.3)$ & $52(22.7)$ & 49 (21.4) & $15(6.6)$ & 45 (19.7) & $94(41.0)$ & $75(32.8)$ \\
\hline Students & $433(65.3)$ & $123(18.6)$ & $69(10.4)$ & $38(5.7)$ & $102(15.2)$ & $184(27.5)$ & 247 (36.9) & $136(20.3)$ \\
\hline Unemployed & - & - & - & - & $47(19.8)$ & $62(26.2)$ & $69(29.1)$ & $59(24.9)$ \\
\hline
\end{tabular}


Table 2 continued

\begin{tabular}{|c|c|c|c|c|c|c|c|c|}
\hline & \multicolumn{4}{|c|}{ Occupational cold exposure } & \multicolumn{4}{|c|}{ Leisure-time cold exposure } \\
\hline & None (NRS 1) & $\begin{array}{l}\text { Low (NRS } \\
2-4)\end{array}$ & $\begin{array}{l}\text { Medium (NRS } \\
5-7 \text { ) }\end{array}$ & $\begin{array}{l}\text { High (NRS } \\
8-10)\end{array}$ & None (NRS 1) & $\begin{array}{l}\text { Low (NRS } \\
2-4)\end{array}$ & $\begin{array}{l}\text { Medium (NRS } \\
5-7 \text { ) }\end{array}$ & $\begin{array}{l}\text { High (NRS } \\
8-10)\end{array}$ \\
\hline & $N(\%)$ & $N(\%)$ & $N(\%)$ & $N(\%)$ & $N(\%)$ & $N(\%)$ & $N(\%)$ & $N(\%)$ \\
\hline $\begin{array}{c}\text { Parental } \\
\text { leave }\end{array}$ & - & - & - & - & $2(3.1)$ & $11(16.9)$ & $29(44.6)$ & $23(35.4)$ \\
\hline Sick leave & - & - & - & - & $35(20.8)$ & $37(22.0)$ & $58(34.5)$ & $38(22.6)$ \\
\hline Retired & - & - & - & - & $437(19.8)$ & $493(22.4)$ & $782(35.5)$ & $490(22.3)$ \\
\hline
\end{tabular}

Self-estimated occupational and leisure-time cold exposure was reported on a ten-point numerical rating scale (NRS) and then separately categorized into four groups ranging from low to high exposures. The exposure was then stratified according to sex, age, region, and occupation. For study subjects that were unemployed, retired, or on parental or sick leave, occupational cold exposure data have been omitted. Data are presented as numbers with percentage within brackets

NRS numerical rating scale

$(17.3 \%)$ and leisure time $(37.0 \%)$ compared to those living in the coastal regions (10.7 and $22.9 \%$, respectively). The highest occupational cold exposure was reported among those working in the armed forces, where $75.8 \%$ reported a high cold exposure during work. Other highly cold-exposed occupational groups were skilled agricultural, forestry, and fishery workers $(67.0 \%)$; crafts and related trades workers (e.g., construction workers) $(29.7 \%)$; plant and machine operators and assemblers $(26.1 \%)$; and elementary occupations (e.g., miners and refuse workers) $(22.5 \%)$. These five occupational groups were all most common in alpine areas and less common in coastal areas (data not shown). The correlation between occupational and leisure-time cold exposure variables was rather low, but statistically significant $\left(r_{\mathrm{s}}=0.27, p\right.$ value $\left.<0.01\right)$. Detailed exposure data can be found in Table 2.

Ever-occurrence of frostbite in the hands was reported by $11.4 \%$ of men and $7.1 \%$ of women, while frostbite in the feet was reported by $10.7 \%$ of men and $9.8 \%$ of women. Facial frostbite was more common at $29.6 \%$ in men and $20.8 \%$ in women. Second- and third-degree frostbite was present in $0.7-2.1 \%$ of men and $0.1-1.0 \%$ in women depending on whether it had occurred in the hands, feet, or face. Sensory hand symptoms in the form of decreased perception of touch, warmth, or cold were reported by 5.6$7.9 \%$ of men and $3.8-7.1 \%$ of women depending on the modality of perception. Certain symptoms occurred specifically in conjunction with cold exposure, such as swollen fingers (9.2\% of men and $15.5 \%$ of women) and pain or discomfort in the hands $(20.4 \%$ of men and $26.5 \%$ of women). Being cold sensitive was reported by $9.7 \%$ of men and $14.4 \%$ of women, and Raynaud's phenomenon was reported by $11.0 \%$ of men and $14.0 \%$ of women. Logistic regression revealed an association between frostbite in the hands and being cold sensitive (men OR 5.02, 95\% CI 3.65-6.90; women OR 5.63, 95\% CI 4.31-7.37) as well as reporting Raynaud's phenomenon (men OR 5.99, 95\% CI 4.94-7.27; women OR 6.59, 95\% CI 5.42-8.01). High cumulative cold exposure was also positively related to the reporting of cold sensitivity (men OR $1.41,95 \%$ CI 1.08 1.85; women $1.77,95 \%$ CI 1.42-2.20) and Raynaud's phenomenon (men OR 1.37, 95\% CI 1.07-1.76; women OR $1.90,95 \%$ CI 1.51-2.39) (Table 3).

\section{Discussion}

The present study shows that cold exposure is common in northern Sweden, both during work and leisure time. However, the correlation between leisure time and occupational exposure is rather low $\left(r_{\mathrm{s}}=0.27, p\right.$ value $<0.01$ ), indicating that the study subjects could be highly exposed in one situation but not in the other. In addition, the exposure to cold is generally greater among men than women and is more pronounced in the rural alpine regions as compared to the urbanized coastal regions, which can be explained by certain outdoor occupations, such as forestry and farming being more common, but also due to outdoor leisure-time activities being more popular in these regions. In addition, the lowest mean temperatures in the study area were found in the alpine regions. Taken together, both behavioral and climatic factors contribute to intensive cold exposure in these areas.

Neurovascular hand symptoms, such as reduced sensory perception, increased cold sensitivity, and Raynaud's phenomenon, were frequently reported and were generally associated with a higher cumulative cold exposure, on a population level. These findings suggest that cold exposure, even in the absence of overt cold injury, such as frostbite or chill blains, might affect the sensory and vascular function of the hands. In addition, previous frostbite to the hands was strongly associated with 
Table 3 Association between cumulative cold exposure and symptoms

\begin{tabular}{|c|c|c|c|c|c|c|c|c|c|}
\hline & & \multicolumn{8}{|c|}{ Cumulative cold exposure } \\
\hline & & \multicolumn{2}{|c|}{$\begin{array}{l}\text { First exposure quar- } \\
\text { tile }(2-5)\end{array}$} & \multicolumn{2}{|c|}{$\begin{array}{l}\text { Second exposure quar- } \\
\text { tile }(6-8)\end{array}$} & \multicolumn{2}{|c|}{$\begin{array}{l}\text { Third exposure quartile } \\
(9-11)\end{array}$} & \multicolumn{2}{|c|}{$\begin{array}{l}\text { Forth exposure quartile } \\
(12-20)\end{array}$} \\
\hline & & $N$ & OR $(95 \% \mathrm{CI})$ & $N$ & OR $(95 \% \mathrm{CI})$ & $N$ & OR $(95 \% \mathrm{CI})$ & $N$ & OR $(95 \% \mathrm{CI})$ \\
\hline \multirow[t]{2}{*}{ Frostbite in hands } & 0 & 81 & $1(-)$ & 123 & $1.18(0.88-1.58)$ & 157 & $1.73(1.31-2.30)^{\mathrm{a}}$ & 246 & $2.29(1.76-2.99)^{\mathrm{a}}$ \\
\hline & q & 85 & $1(-)$ & 143 & $1.78(1.35-2.34)^{\mathrm{a}}$ & 152 & $2.61(1.98-3.43)^{\mathrm{a}}$ & 82 & $2.40(1.75-3.28)^{\mathrm{a}}$ \\
\hline \multirow[t]{2}{*}{ Frostbite in feet } & 0 & 71 & $1(-)$ & 129 & $1.43(1.06-1.94)^{\mathrm{a}}$ & 163 & $2.10(1.57-2.81)^{\mathrm{a}}$ & 213 & $2.23(1.69-2.96)^{\mathrm{a}}$ \\
\hline & q & 113 & $1(-)$ & 211 & $2.02(1.59-2.56)^{\mathrm{a}}$ & 195 & $2.56(2.01-3.26)^{\mathrm{a}}$ & 119 & $2.71(2.07-3.56)^{\mathrm{a}}$ \\
\hline \multirow[t]{2}{*}{ Frostbite in face } & o & 185 & $1(-)$ & 361 & $1.67(1.37-2.04)^{\mathrm{a}}$ & 430 & $2.47(2.03-3.01)^{\mathrm{a}}$ & 606 & $3.02(2.50-3.65)^{\mathrm{a}}$ \\
\hline & \% & 284 & $1(-)$ & 462 & $1.85(1.57-2.18)^{\mathrm{a}}$ & 394 & $2.20(1.86-2.61)^{\mathrm{a}}$ & 211 & $1.99(1.63-2.42)^{\mathrm{a}}$ \\
\hline \multirow[t]{2}{*}{ Reduced sensitivity to touch } & 0 & 64 & $1(-)$ & 85 & $1.02(0.73-1.43)$ & 91 & $1.23(0.88-1.71)$ & 179 & $2.05(1.52-2.75)^{\mathrm{a}}$ \\
\hline & q & 118 & $1(-)$ & 126 & $1.09(0.84-1.42)$ & 108 & $1.26(0.96-1.65)$ & 92 & $1.93(1.45-2.57)^{\mathrm{a}}$ \\
\hline \multirow[t]{2}{*}{ Reduced sensitivity to warmth } & 0 & 57 & $1(-)$ & 69 & $0.93(0.65-1.33)$ & 60 & $0.89(0.62-1.29)$ & 131 & $1.64(1.19-2.26)^{\mathrm{a}}$ \\
\hline & q & 67 & $1(-)$ & 79 & $1.21(0.87-1.69)$ & 88 & $1.83(1.32-2.54)^{\mathrm{a}}$ & 68 & $2.49(1.76-3.52)^{\mathrm{a}}$ \\
\hline \multirow[t]{2}{*}{ Reduced sensitivity to cold } & 0 & 49 & $1(-)$ & 58 & $0.90(0.61-1.33)$ & 67 & $1.17(0.81-1.71)$ & 116 & $1.68(1.19-2.37)^{\mathrm{a}}$ \\
\hline & q & 61 & $1(-)$ & 66 & $1.10(0.77-1.57)$ & 54 & $1.20(0.83-1.75)$ & 43 & $1.68(1.13-2.51)^{\mathrm{a}}$ \\
\hline \multirow[t]{2}{*}{ Swollen fingers when cold } & 0 & 68 & $1(-)$ & 108 & $1.24(0.90-1.69)$ & 129 & $1.69(1.24-2.29)^{\mathrm{a}}$ & 187 & $2.02(1.51-2.69)^{\mathrm{a}}$ \\
\hline & q & 236 & $1(-)$ & 306 & $1.38(1.15-1.66)^{\mathrm{a}}$ & 290 & $1.83(1.52-2.20)^{\mathrm{a}}$ & 172 & $1.88(1.52-2.33)^{\mathrm{a}}$ \\
\hline \multirow[t]{2}{*}{ Cold sensitivity } & 0 & 86 & $1(-)$ & 126 & $1.14(0.85-1.51)$ & 131 & $1.33(1.00-1.77)^{\mathrm{a}}$ & 170 & $1.41(1.08-1.85)^{\mathrm{a}}$ \\
\hline & q & 239 & $1(-)$ & 263 & $1.15(0.95-1.39)$ & 251 & $1.52(1.26-1.84)^{\mathrm{a}}$ & 164 & $1.77(1.42-2.20)^{\mathrm{a}}$ \\
\hline \multirow[t]{2}{*}{ Pain or discomfort in hands when cold } & 0 & 168 & $1(-)$ & 251 & $1.18(0.95-1.46)$ & 270 & $1.46(1.18-1.80)^{\mathrm{a}}$ & 389 & $1.77(1.45-2.17)^{\mathrm{a}}$ \\
\hline & q & 410 & $1(-)$ & 528 & $1.42(1.23-1.65)^{\mathrm{a}}$ & 462 & $1.74(1.50-2.04)^{\mathrm{a}}$ & 289 & $1.97(1.65-2.35)^{\mathrm{a}}$ \\
\hline \multirow[t]{2}{*}{ Raynaud's phenomenon } & 0 & 103 & $1(-)$ & 135 & $1.01(0.77-1.32)$ & 138 & $1.16(0.88-1.51)$ & 198 & $1.37(1.07-1.76)^{\mathrm{a}}$ \\
\hline & ㅇ & 198 & $1(-)$ & 303 & $1.66(1.37-2.00)^{\mathrm{a}}$ & 250 & $1.85(1.52-2.26)^{\mathrm{a}}$ & 147 & $1.90(1.51-2.39)^{\mathrm{a}}$ \\
\hline
\end{tabular}

Self-estimated occupational and leisure-time cold exposure, reported on two separate ten-point numerical rating scales (NRS), has been added together to form a cumulative measurement of cold exposure ranging from 2 to 20 . The data were subsequently divided into quartiles, and the first quartile is set as the reference. Associations are presented as odds ratios (OR) with $95 \%$ confidence intervals (95\% CI)

$N R S$ numerical rating scale, $O R$ odds ratio, $C I$ confidence interval

${ }^{a}$ Bold values indicate odds ratios with significant $95 \%$ confidence intervals

both cold sensitivity and Raynaud's phenomenon, which might indicate a common pathophysiological mechanism for these conditions. We hypothesize that cold exposure might cause neurovascular dysfunction in exposed body parts, such as the hands, and give rise to the aforementioned symptoms. There is some, although limited, laboratory (Hope et al. 2014) and epidemiological (Block and Sequeira 2001; Mackiewicz and Piskorz 1977) data to support this concept. Even though cold exposure was generally more pronounced among men, cold-related symptoms were more frequently reported by women. This might be interpreted as a particular susceptibility among women, and this warrants further research.

Previous studies have reported that men are generally more exposed to cold climate, especially those working in farming, forestry, industry, or construction (Makinen et al. 2006). The same pattern was seen in the present study. The anthropometric data, tobacco use, and disease spectrum in our cohort (Table 1) roughly corresponded with other recent Swedish investigations (Backman et al. 2014; Eriksson et al. 2010; Lindberg et al. 2006), which indicates that our study has included a representative sample of the population. Other authors have reported that frostbite is common in circumpolar areas (Ikaheimo and Hassi 2011), with a prevalence of serious frostbite of $1.5 \%$ for men and $0.5 \%$ for women in Finland (Raatikka et al. 2007), which is similar to our results. Regarding sensory hand symptoms, a recently published study on heavily cold-exposed Swedish military conscripts showed a significant decrease in sensory perception after winter training, which was evident even among those without any reported cold injury (Carlsson et al. 2016). The prevalence of Raynaud's phenomenon in our study was high compared to previous studies on a general population, especially among men. In a recent review, the prevalence of Raynaud's phenomenon was estimated to be $0.8-6.5 \%$ in men and $2.1-5.8 \%$ in women, with the exact figure depending on the region in which the study was conducted 
and how a case was defined (Garner et al. 2015). However, in the aforementioned Finnish study (Raatikka et al. 2007), the prevalence of Raynaud's phenomenon was $11.9 \%$ for men and $12.4 \%$ for women, which compares well with our results showing a occurrence of $11.0 \%$ for men and $14.0 \%$ for women. Such a high occurrence might indicate secondary etiologies, such as hand-arm vibration injury or auto-immune diseases, but the cold climate in Sweden and Finland might also trigger Raynaud's phenomenon and other hand symptoms more easily than in a warmer climate, a notion that is supported by epidemiological data (Block and Sequeira 2001).

There are several limitations to our study. The crosssectional design does not allow causal relations to be established. The rather low response rate $(35.9 \%)$ may limit the generalizability of the results and increase the uncertainty in prevalence estimates. There is also the possibility that symptomatic subjects might be more prone to respond to a questionnaire of this kind, and this might lead to an overestimation of both exposure and symptoms. The number of retired respondents was high, which might weaken any possible associations with occupational factors. The study region comprises a large area with a mean monthly temperature during the study period that spanned from about -9 to $5{ }^{\circ} \mathrm{C}$, meaning that there is reason to suspect a variance in ambient cold exposure that has not been adjusted for in the analyses. Thus, the results in our study serve as an indication of health effects due to cold exposure in northern Sweden, but must be cautiously interpreted with regard to these limitations in study design and response rate.

Despite these limitations, this is the first populationbased study on cold exposure and related health effects in Sweden, and it includes more than 12,000 participants. Despite the rather low response rate, the high occurrence of cold-related symptoms in the cohort still indicates that cold exposure poses a significant negative impact on health in northern Sweden. Our analysis revealed no major differences between responders and non-responders regarding geographical region, which was the expected main determinant of the cold exposure variables (Online Resource 1). Thus, we believe that the present study has included a representative sample of the population and that the possible bias produced by a low response rate has not affected the exposure data to any great extent. The cold exposure in our study was estimated from a subjective standpoint, but the close association between cumulative cold exposure and the occurrence of frostbite (which we consider as a definitive marker of cold exposure) supports that this approach to collecting exposure data was relevant (Table 3). This first study within CHINS will provide a baseline cohort for questionnaire-based case-control studies focusing on different cold-related health effects.

\section{Conclusion}

The present study demonstrates that the cold environment in northern Sweden might be an underestimated health risk. Our hypothesis that cold exposure is positively related to reporting of neurovascular hand symptoms was supported by our findings. In addition, such symptoms were common not only in conjunction with an overt cold injury. Our results warrant further study on pathophysiological mechanisms and suggest the need for confirmatory prevalence studies to support national public health planning.

Acknowledgements We gratefully acknowledge the valuable contributions of Daniel Carlsson and Dr. Hans Pettersson at the Department of Public Health and Clinical Medicine at Umeå University.

\section{Compliance with ethical standards}

All procedures performed in studies involving human participants were in accordance with the ethical standards of the institutional and/ or national research committee and with the 1964 Helsinki declaration and its later amendments or comparable ethical standards. The study protocol was approved by the Regional Ethical Review Board situated at Umeå University (DNR 2015-24-31 M and 2014-286-31 M).

Conflict of interest The authors declare that they have no conflict of interest.

Informed consent Informed consent was obtained from all individual participants included in the study.

Funding Financial support was provided through a regional agreement between Umeå University and Västerbotten County Council.

Open Access This article is distributed under the terms of the Creative Commons Attribution 4.0 International License (http://creativecommons.org/licenses/by/4.0/), which permits unrestricted use, distribution, and reproduction in any medium, provided you give appropriate credit to the original author(s) and the source, provide a link to the Creative Commons license, and indicate if changes were made.

\section{References}

Backman H, Hedman L, Jansson SA, Lindberg A, Lundback B, Ronmark E (2014) Prevalence trends in respiratory symptoms and asthma in relation to smoking-two cross-sectional studies ten years apart among adults in northern Sweden. World Allergy Organ J 7:1. doi:10.1186/1939-4551-7-1

Baldus S, Kluth K, Strasser H (2012) Order-picking in deep coldphysiological responses of younger and older females. Part 2: body core temperature and skin surface temperature. Work 41(1):3010-3017. doi:10.3233/WOR-2012-0557-3010 
Block JA, Sequeira W (2001) Raynaud's phenomenon. Lancet 357:2042-2048. doi:10.1016/S0140-6736(00)05118-7

Carlsson IK, Rosen B, Dahlin LB (2010) Self-reported cold sensitivity in normal subjects and in patients with traumatic hand injuries or hand-arm vibration syndrome. BMC Musculoskelet Disord 11:89. doi:10.1186/1471-2474-11-89

Carlsson D, Pettersson H, Burstrom L, Nilsson T, Wahlstrom J (2016) Neurosensory and vascular function after 14 months of military training comprising cold winter conditions. Scand $\mathbf{J}$ Work Environ Health 42:61-70. doi:10.5271/sjweh.3530

Eriksson M, Holmgren L, Janlert U, Jansson JH, Lundblad D, Stegmayr B et al (2010) Large improvements in major cardiovascular risk factors in the population of northern Sweden: the MONICA study 1986-2009. J Int Med 269:219-231. doi:10.1111/j.1365-2796.2010.02312.x

Garner R, Kumari R, Lanyon P, Doherty M, Zhang W (2015) Prevalence, risk factors and associations of primary Raynaud's phenomenon: systematic review and meta-analysis of observational studies. BMJ Open 5:e006389. doi:10.1136/ bmjopen-2014-006389

Gasparrini A, Guo Y, Hashizume M, Lavigne E, Zanobetti A, Schwartz J et al (2015) Mortality risk attributable to high and low ambient temperature: a multicountry observational study. Lancet 386:369-375. doi:10.1016/S0140-6736(14)62114-0

Hagberg M, Burstrom L, Lundstrom R, Nilsson T (2008) Incidence of Raynaud's phenomenon in relation to hand-arm vibration exposure among male workers at an engineering plant a cohort study. J Occup Med Toxicol 3:13

Hassi J, Rytkonen M, Kotaniemi J, Rintamaki H (2005) Impacts of cold climate on human heat balance, performance and health in circumpolar areas. Int J Circumpolar Health 64:459-467

Hope K, Eglin C, Golden F, Tipton M (2014) Sublingual glyceryl trinitrate and the peripheral thermal responses in normal and cold-sensitive individuals. Microvasc Res 91:84-89. doi:10.1016/j.mvr.2013.11.002

Ikaheimo TM, Hassi J (2011) Frostbites in circumpolar areas. Glob Health Action 4:8456. doi:10.3402/gha.v4i0.8456

Imray CH, Castellani JW (2012) Nonfreezing Cold-Induced Injuries. In: Auerbach PS (ed) Wilderness Medicine, 6th edn. Elsevier, Philadelphia, pp 171-180

Imray $\mathrm{CH}$, Grieve A, Dhillon S, The Caudwell Xtreme Everest Research Group (2009) Cold damage to the extremities: frostbite and non-freezing cold injuries. Postgrad Med J 85:481488. doi:10.1136/pgmj.2008.068635

International Labour Organization (2012) International Standard Classification of Occupations (ISCO-08), Geneva, Switzerland. ISBN 978-92-2-125953-4

International Organization for Standardization (2008) ISO 15743:2008—Ergonomics of the thermal environment—Cold workplaces-Risk assessment and management, Brussels

Kay S (1985) Venous occlusion plethysmography in patients with cold related symptoms after digital salvage procedures. J Hand Surg Br 10:151-154

Keim SM, Guisto JA, Sullivan JB Jr (2002) Environmental thermal stress. Ann Agric Environ Med 9:1-15
Lindberg A, Bjerg A, Ronmark E, Larsson LG, Lundback B (2006) Prevalence and underdiagnosis of COPD by disease severity and the attributable fraction of smoking: report from the obstructive lung disease in Northern Sweden studies. Respir Med 100:264-272. doi:10.1016/j.rmed.2005.04.029

Lithell M, Backman C, Nystrom A (1997) Pattern recognition in post-traumatic cold intolerance. J Hand Surg Br 22:783-787

Mackiewicz Z, Piskorz A (1977) Raynaud's phenomenon following long-term repeated action of great differences of temperature. J Cardiovasc Surg (Torino) 18:151-154

Makinen TM, Hassi J (2002) Usability of isothermal standards for cold risk assessment in the workplace. Int $\mathrm{J}$ Circumpolar Health $61: 142-153$

Makinen TM, Hassi J (2009) Health problems in cold work. Ind Health 47:207-220

Makinen TM, Raatikka VP, Rytkönen M, Jokelainen J, Rintamäki $\mathrm{H}$, Ruuhela $\mathrm{R}$ et al (2006) Factors affecting outdoor exposure in winter: population-based study. Int J Biometeorol 51:27-36. doi:10.1007/s00484-006-0040-0

Makinen TM, Jokelainen J, Näyhä S, Laatikainen T, Jousilahti P, Hassi J (2009) Occurrence of frostbite in the general population-work-related and individual factors. Scand J Work Environ Health 35:384-393

Nayha S, Hassi J, Jousilahti P, Laatikainen T, Ikaheimo TM (2011) Cold-related symptoms among the healthy and sick of the general population: national FINRISK Study data, 2002. Public Health 125:380-388. doi:10.1016/j.puhe.2011.02.014

Negro C, Rui F, D’Agostin F, Bovenzi M (2008) Use of color charts for the diagnosis of finger whiteness in vibration-exposed workers. Int Arch Occup Environ Health 81:633-638. doi:10.1007/ s00420-007-0248-2

Raatikka VP, Rytkonen M, Nayha S, Hassi J (2007) Prevalence of cold-related complaints, symptoms and injuries in the general population: the FINRISK 2002 cold substudy. Int J Biometeorol 51:441-448. doi:10.1007/s00484-006-0076-1

Swedish metrological and hydrological institute (2015) National Weather Data Report. www.smhi.se/klimatdata/meteorologi/temperatur. Accessed 20 Dec 2015

Swedish Work Environment Authority (2014) The Work Environment 2013, Report no. 2014:3, Stockholm: Swedish Work Environment Authority

The Eurowinter Group (1997) Cold exposure and winter mortality from ischaemic heart disease, cerebrovascular disease, respiratory disease, and all causes in warm and cold regions of Europe. Lancet 349:1341-1346

The Swedish horticultural society (2015) Climate zones for gardening. www.tradgard.org/svensk_tradgard/zonkartan.html. Accessed 11 Jan 2015

Thomas JR, Oakley HN (2002) Nonfreezing cold injury. In: Pandoff $\mathrm{KB}$, Burr RE (eds) Medical aspects of harsh environments, textbooks of military medicine, vol 1, 1st edn. Walter Reed Army Medical Center, Washington, pp 467-490 